\title{
Inteligência Artificial e Educação Especial: Desafios Éticos
}

\author{
Francisco Dutra dos Santos Jr. ${ }^{1}$, Dante Couto Barone ${ }^{1}$, Leandro Krug Wives ${ }^{1}$, Igor \\ Kuhn $^{1}$
}

\footnotetext{
${ }^{1}$ CINTED/PPGIE - Programa de Pós-Graduação em Informática na Educação Universidade Federal do Rio Grande do Sul (UFRGS) - Caixa Postal 90.040- 060 Porto Alegre - RS - Brazil

prof.chicosantosjr@gmail.com, baronedinf.ufrgs.br, wives@inf.ufrgs.br, kunhigoregmail.com
}

\begin{abstract}
This article proposes to discuss a brief outline of Artificial Intelligence and its application possibilities in Special Education. It presents as scope the ethical repercussion of existing and possible educational applications. It follows three guiding principles, the legislation on Inclusion of people with disabilities, the Global Initiative guidelines on Ethics of Autonomous and Intelligent Systems, and the Beijing Consensus on Artificial Intelligence and Education. Analysis consists in putting into perspective the advances of the I.A. as possibilities in the inclusion process of students with special educational needs. However, with full attention to the ethical dilemmas already advocated in the field of Artificial Intelligence.
\end{abstract}

Resumo. Este artigo propõe-se a discutir breve recorte da Inteligência Artificial e suas possibilidades de aplicação na Educação Especial. Apresenta como escopo a repercussão ética das existentes e possíveis aplicações educacionais. Segue três eixos norteadores, a legislação correspondente a Inclusão das pessoas com deficiências, as diretrizes da Global Iniciative on Ethics of Autonomous and Intelligent Systems, e o Consenso de Pequim sobre Inteligência Artificial e Educação. Análise consiste colocar em perspectiva os avanços da I.A. como possibilidades no processo de inclusão de alunos com necessidades educacionais especiais. Porém, com a atenção plena aos dilemas éticos, já preconizados, no campo da Inteligência Artificial. 


\section{Introdução}

O presente artigo busca discutir os recentes pressupostos éticos da Inteligência Artificial com os atuais e futuros estudos de sua aplicação no âmbito da Educação Especial. Pois, as práticas e políticas pedagógicas na Educação Especial e Educação Inclusiva estão permeadas por fundamentos éticos, devido a intervenção e mediação com sujeitos que se apresentam com múltiplas diversidade. A proposição analítica consiste na discussão entre três eixos de documentos de princípios norteadores da Educação Especial/Educação Inclusiva, Educação e I.A.

\section{Educação Especial/Inclusiva}

Ao agregar o uso das tecnologias, novos cenários se abrem, como demandas específicas e necessárias no campo da ética. O escopo da ética torna-se relevante pela própria trajetória da Educação Especial, na medida em que diferentes posições foram tomadas em relação à visão de sujeitos com deficiência no percurso histórico da sua escolarização. Pois, a vigência do paradigma da inclusão de estudantes com Necessidades Educacionais Especiais-NEEs, no contexto regular de ensino remete para profundas mudanças atitudinais, físicas e educacionais. Nesse sentido, o uso das tecnologias passa a ocupar um papel importante, na medida em que a ampliação de seus campos de aplicação se estende para a educação, tais como a Inteligência Artificial.

\section{Inteligência Artificial na Educação}

Tecnologias educacionais inovadoras começaram a abrir novas formas de interagir com alunos com necessidades educacionais especiais (NEE). Entre as abordagens mais eficazes durante a última década (2001-2010) são aquelas baseadas nas técnicas de Inteligência Artificial (IA). A aplicação da IA como método é vista como um meio de melhorar a qualidade de vida dos alunos com NEE.

\section{A Ética como desafio}

Pesquisadores do mundo inteiro se debruçaram por meio de comitês a fim de discutir as varias dimensões da ética, com dilemas, conflitos e seus problemas. Nesse sentido, os impactos da IA na educação tem profunda repercussão porém, a transversalidade ética no campo da Educação Especial/Inclusiva. A apropriação de tecnologias que utilizam a inteligência artificial é bastante relevante, especialmente em suas dimensões éticas, quando essas responsabilidades são pertencentes aos sistemas educacionais de ensino.

No Consenso de Pequim Sobre Inteligência Artificial e Educação (2019) é reafirmado que a busca da inclusão e da equidade deve ocorrer por meio de uma educação cuja disposição possa oferecer oportunidade de aprendizagem ao longo da vida para todos. Reafirma, que avanços tecnológicos com uso da IA na educação devem oportunizar a ampliação do acesso à educação para grupos mais vulneráveis. No que consiste promover aprendizado de alta qualidade independente de gênero, deficiência, status social ou econômico, origem étnica, cultural ou localização geográfica. O uso da IA 
deve estar à serviço da redução do fosso digital e dos preconceitos contra minorias. É fortemente recomendado que seja garantido o uso de ferramentas de ensino e aprendizagem baseadas na IA a fim de favorecer a inclusão de alunos com dificuldades de aprendizagem.

\section{Considerações Finais}

Análise demonstrou a necessidade de ampliar os estudos sobre a repercussão do uso da IA na Educação Especial e Inclusiva na perspectiva ética das suas aplicações e nas políticas educativas. Holmes, Bialik, Fadel (2019), destacam as seguintes questões que devem ser tomadas como desafios: Que critérios para a Educação em AI são eticamente aceitáveis. Como a natureza transitória dos objetivos, interesses e emoções dos alunos afeta a ética da AI na Educação? Quais são as obrigações éticas ligadas as organizações privadas (desenvolvedores de produtos de AI-Educação) e das autoridades públicas (escolas e universidades envolvidas na pesquisa da AI-Educação)? Como as escolas, os alunos e os professores podem optar por não participar ou até mesmo desafiar sua representação nas bases de dados? Quais são as implicações éticas dos sujeitos não serem capazes de questionar facilmente as decisões mias profundas da AI-Educação (usando redes neurais multiníveis)?

\section{Referências}

Aguiar, J. Hermosilla, L. Aplicações da Inteligência Artificial na Educação. Ano IV - Número 06 - Fevereiro de 2007 - Periódicos Semestral. Revista Científica Eletrônica de Sistema de informações é uma publicação semestral da Faculdade de Ciências de Ciências Jurídicas e gerenciais FAEG/FAEF e Editora FAEF.

Barreto, J. M. Inteligência Artificial no Limiar do Século XXI - Abordagem Híbrida, Simbólica, Conexionista e Evolucionária. UFSC, 2001.

ETHICALLY ALIGNED DESIGN A Vision for Prioritizing Human Well-being with Autonomous and Intelligent Systems. IEE, 2016.

Holmes, W., Bialik M., Fadel C. Artificial Intelligence in Education: Promises and Implications for Teaching and Learning.The Center for Curriculum Redesign, Boston, MA, 2019.

MEC/SECADI. Política Nacional de Educação Especial na Perspectiva da Educação Inclusiva, 2008.

UNESCO. CONSENSUS DE BEIJING SUR L'INTELLIGENCE ARTIFICIELLE ET L'ÉDUCATION: Document final de la Conférence internationale sur l'intelligence artificielle et l'éducation «Planifier l'éducation à l'ère de l'IA : un bond en avant ». 16-18 mai 2019, Beijing, République populaire de Chine.

Vicari, R. M. Inteligência Artificial aplicada à Educação. In: Pimentel, M; Sampaio, F. F.; Santos, E. O. (Org.). Informática na Educação: técnicas e tecnologias computacionais. Porto Alegre: Sociedade Brasileira de Computação, 2019. (Série Informática na Educação, v.4). 